\title{
The standardised admission ratio for measuring widening participation in medical schools: analysis of UK medical school admissions by ethnicity, socioeconomic status, and sex
}

Kieran Seyan, Trisha Greenhalgh, Danny Dorling

Ethnic minorities and women are no longer underrepresented in UK medical schools, but lower socioeconomic groups still are. ${ }^{1}$ Given the strong political pressure on higher education institutions to develop "widening participation" programmes, ${ }^{23}$ a valid quantitative index of the impact of such programmes is needed urgently. Such an index should be derived from robust and accessible primary data, reflect the impact of multiple independent variables in different population subgroups, allow comparisons across institutions and over time, and be readily understandable by non-statisticians.

Statistics on the entry profile of UK medical schools are usually expressed as the selection ratio (the proportion of admissions to applications ${ }^{4}$ ). We propose that the standardised admission ratio (see box), which expresses the number of pupils admitted to medical school as a proportion of the number who would do so if places were allocated equitably across all socioeconomic and ethnic groups and equally by sex, should become the standard measure of widening participation. It would not, of course, be an index of discrimination at selection stage.

\section{Methods and results}

We calculated standardised admission ratios using data from the Universities' Central Admissions Service database (www.ucas.ac.uk/figures) on UK medical school admissions from 1996 to 2000 (the last year for which full figures are so far available, and the last year in which socioeconomic status was measured in traditional social class bands) as a numerator and the labour force survey (www.statistics.gov.uk) as a denominator (see figure).

Using the values for 2000, we found that standardised admission ratios varied around 10-fold by ethnicity-from 6.07 in Asians (over-represented) to 0.73 in white people (under-represented)-and around 30 -fold by social class-from 6.76 in social class I to 0.20 in class $\mathrm{V}$ (see table on bmj.com). But when we calculated the ratios by ethnicity and social class they varied 600 -fold from the most over-represented group with a significant denominator (Asians from social class I, 41.73) to the most under-represented group with fewest admissions (black people from social class IV, 0.07; no black people from social class $\mathrm{V}$ were admitted to medical school from 1996 to 2000).

White and black pupils from social class I were around 100 times more likely to gain a place at medical school than those from classes IV or V. Asian pupils seemed to compensate better for poor origins, but those from social class I were still 6-10 times more likely to gain a place than those from classes IV or V. The standardised admission ratio for women increased

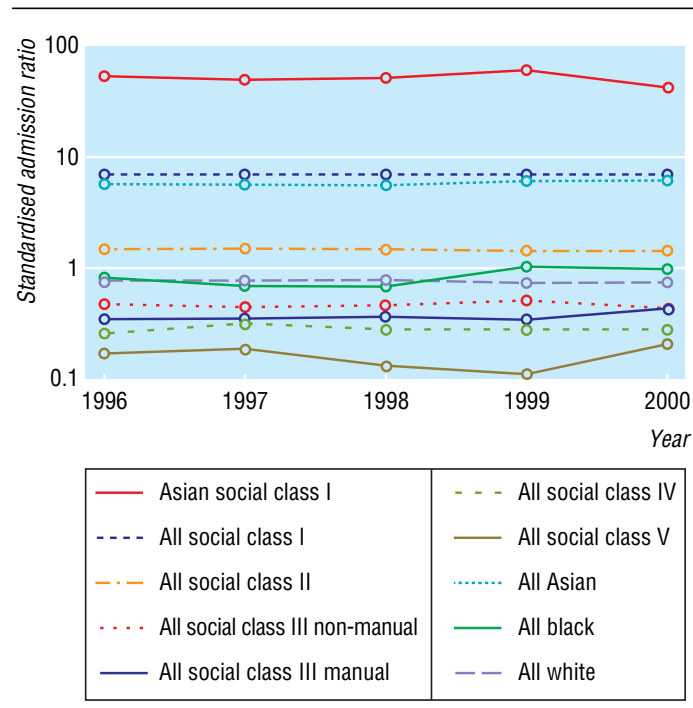

Standardised admission ratios by social class and ethnicity for UK medical school admissions 1996-2000 (log scale)

from 1.08 in 1996 to 1.15 in 2000, and that for men fell correspondingly. Sex specific standardised admission ratios did not vary significantly by socioeconomic status, but they did vary by ethnicity, with Asians having similar ratios for men and women but black and white men being significantly under-represented compared with women.

\section{Comment}

We found massive inequalities in medical school admissions by social class. Although the confidence intervals around individual values are likely to be high, especially in subgroups with small denominators, the overall picture is probably valid. It should not be assumed that the ideal situation is for the standardised admission ratio for all population subgroups to be 1.0, since this would imply that all contain equal proportions of pupils who are suitable for a medical career-an implausible hypothesis. The standardised

\section{Definition of the standardised admission ratio for applicants to} medical school

No of admissions from a particular population subgroup as a proportion of all admissions

Proportion of the general population that belongs to that subgroup

A table detailing calculation of standardised admission ratios

+ for different population groups appears on bmj.com 


\section{What is already known about this topic}

"Widening participation"-that is, encouraging pupils from non-traditional groups into higher education-is currently a political priority in Britain

There is no agreed index by which medical schools can measure their success in widening participation

\section{What this study adds}

We have developed an index of widening participation that is easily calculated from publicly available data and which allows comparisons by sex, ethnicity, and socioeconomic status; between medical schools; and across time

admission ratio is a composite index-being derived from both the proportion of people who apply to medical school in any subgroup and the proportion of applicants who get accepted-and hence should be interpreted with caution.

With these caveats, we believe the standardised admission ratio will be a useful "bottom line" index for quantifying the inequalities in medical school entry (and entry to any higher education course) between subgroups as widening participation initiatives are implemented and evaluated. In our companion paper, we explore the reasons for the wide differences in admission by social class. ${ }^{5}$

We thank Janet Grant for advice on medical admissions datasets, George Davey Smith for advice on the measurement of social class, and three referees for helpful comments on earlier drafts of this paper.

Contributors: KS conceptualised the study and undertook the initial data collection and analysis. TG assisted with data analysis and interpretation. DD provided statistical advice. TG is guarantor for the study.

Funding: None. This project was part of a BSc dissertation by KS.

Competing interests: None declared.

1 Secretary of State for Education. Medical schools: delivering the doctors of the future. London: Department for Education and Skills, 2004.

2 Universities UK. Fair enough:wider access to university by identifying potential to succeed. London: Universities UK, 2003.

3 Higher Education Funding Council. Social class and participation: good practice in widening access to education (follow-up to 'From elitism to inclusion') London: Higher Education Funding Council, 2003

4 McManus IC. Medical school applications-a critical situation. BMJ 2002;325:786-7

5 Greenhalgh T, Seyan K, Boynton P. "Not a university type”: focus group study of social class, ethnic, and sex differences in school pupils' perceptions about medical school. BMJ 2004;328:1541-4.

(Accepted 21 April 2004)

\section{A memorable patient}

\section{Caring for those who refuse help}

John is 85 years old, and his condition has been getting worse over the past few months. He is forgetful, not taking his drugs, and forgetting to eat his "meals on wheels." His family are helpful but cannot be with him all day. His prostate specific antigen concentration is sky high, and nobody knows quite what happened when he went to the urology outpatient clinic: he never saw the registrar and somehow found his own way home.

The deputising GP service saw him last night and said he must be urgently reviewed today, Saturday. He is lying on the floor, crumpled, his pants are soiled, and his food is down his trousers. His mini-mental state score is 13 . He has dementia and is prone to falling over. His digoxin box should be half empty, but it is still sealed.

He is beyond the scope of home care and needs to be in hospital, but he has other views: "Please don't make me go there again."

"I think we need to get you seen in hospital, just to make sure there isn't anything wrong. If I get an ambulance will you go with them?"

"No." His intention is clear. He needs to be admitted, and it will have to be against his will.

The psychiatrists are very supportive but feel that, even though he spent Wednesday night in casualty, he needs to be seen by the "medics." The health care of the elderly team are a little hesitant but agree to assess him to exclude an "organic cause." But he still will not go in the ambulance. The view from the social worker and psychiatrist is that we can admit him under common law for his own protection. Ambulance control say they will not take him against his will unless he has been "sectioned" under the Mental Health Act, and they want the police present. The police will only attend to prevent a breach of the peace.

Time to speak to the consultant, who agrees to let the registrar assess him under the Mental Health Act, so finally we all meet in John's bedroom. We talk about Rosie, his dead wife, and how she keeps an eye on him. He does not agree to go to hospital, but he is tired and doesn't actually refuse. The ambulance crew swaddle him in a red blanket and carry him downstairs. We have been at this for five hours.

"Would you have sectioned him if he had refused?" I ask the psychiatrists.

"Oh no," they reply. "He isn't mentally ill."

There seems to be a huge hole opening up in care for those with dementia. This man needed sanctuary, where he could be cared for; all of the teams agreed this, yet nobody could actually agree to deliver it. Even though this patient had marked dementia, a mental illness, he is not regarded as being "mentally ill." Even though he is just as much a risk to himself as people with other severe mental illness, the law (under the Mental Health Act) does not protect him. The suggestion that we could treat him under common law (that is, where no law is written down) does not wash with ambulance and police teams, who are concerned about accusations of assault.

It is time to reconsider the scope of the Mental Health Act and stop this artificial and spurious distinction between organic and psychiatric causation of symptoms, and to use the act to protect those who refuse treatment but are "mentally ill" in a broader sense and at real risk to themselves.

John died three weeks after being admitted.

Melvyn Jones lecturer in general practice, department of primary care and population sciences, Royal Free and University College Medical School, London

We welcome articles up to 600 words on topics such as A memorable patient, A paper that changed my practice, My most unfortunate mistake, or any other piece conveying instruction, pathos, or humour. Please submit the article on http:// submit.bmj.com Permission is needed from the patient or a relative if an identifiable patient is referred to. We also welcome contributions for "Endpieces," consisting of quotations of up to 80 words (but most are considerably shorter) from any source, ancient or modern, which have appealed to the reader. 